\title{
Extubation success without using high-flow nasal cannula and non-invasive ventilation for patients with coronavirus disease 2019 (COVID-19): A retrospective observational study
}

Akira Inoue ( $\sim$ lac.2.eueykn@gmail.com)

Kawasaki Shiritsu Kawasaki Byoin https://orcid.org/0000-0001-5868-5186

Kazuhiro Shirakawa

Kawasaki Shiritsu Kawasaki Byoin

Nonoka Fujita

Kawasaki Shiritsu Kawasaki Byoin

Kunio Kanao

Kawasaki Shiritsu Kawasaki Byoin

Yutaka Saito

Kawasaki Shiritsu Kawasaki Byoin

Kiyotsugu Takuma

Kawasaki Shiritsu Kawasaki Byoin

\section{Research}

Keywords: extubation, reintubation, COVID-19, HFNC, NIV, NPPV

Posted Date: August 26th, 2020

DOI: https://doi.org/10.21203/rs.3.rs-64389/v1

License: (c) (i) This work is licensed under a Creative Commons Attribution 4.0 International License.

Read Full License 


\section{Abstract}

Background In March 2020, the World Health Organization declared coronavirus disease 2019 (COVID-19) to be a global pandemic. It was also reported that approximately $20 \%-23 \%$ of patients with COVID-19 admitted to the hospital required mechanical ventilation (MV). Reintubation rates ranged from 13-19\%, leading to increased mortality. Moreover, exposure of health care workers is a serious problem and intubation is a high-risk procedure because of aerosol generation. To reduce reintubation, preventive highflow nasal cannula (HFNC) and non-invasive ventilation (NIV) after extubation are recommended. However, using HFNC and NIV in patients with COVID-19 may lead to the spread of infection. Without using HFNC and NIV, conventional spontaneous breathing trial (SBT) may overestimate a patient's respiratory status. A highly demanding SBT accurately assesses a patient's reserve capacity and may reduce reintubation. We did not use preventive HFNC or NPPV and extubated with a highly demanding SBT protocol. This study aimed to evaluate whether our protocol can be performed safely.

Methods This single-centre study was conducted at the Kawasaki Municipal Hospital from February 2020 to June 2020. Patients with COVID-19 requiring MV were screened for their eligibility for the weaning procedure every day. Patients were extubated after administering methylprednisolone if SBT was well tolerated. SBT was performed with $3 \mathrm{cmH}_{2} \mathrm{O}$ pressure support, $3 \mathrm{cmH}_{2} \mathrm{O}$ positive end-expiratory pressure, and $\leq 0.30$ fraction of inspired oxygen. In extubated patients, the reintubation rate, duration of $\mathrm{MV}$, length of intensive care unit (ICU) and hospital stay, and rate of ventilator-associated pneumonia (VAP) were analyzed.

Results Ten patients received MV. Two of 10 patients had no improvement in their respiratory status and did not qualify for the extubation criteria and died. Eight patients were extubated. No reintubations were performed $(0 \%)$. The median durations of MV, ICU stay, and hospital stay were 13 (interquartile range [IQR], 10-16) days, 17 (IQR, 13-27) days, and 22 (IQR, 16-26), and 3 patients (37.5\%) was diagnosed VAP.

Conclusions Extubation was performed with a highly demanding SBT protocol, and no patients were reintubated. All patients did not require HFNC and NIV. Further research is required in critically ill patients.

\section{Background}

In March 2020, the World Health Organization (WHO) declared coronavirus disease 2019 (COVID-19), caused by the severe acute respiratory syndrome coronavirus 2, a global pandemic. As of June 30, 2020, the WHO has reported 10,268,839 COVID-19 cases and 506,064 deaths worldwide [1]. It has also been reported that approximately $20 \%-23 \%$ of patients with COVID-19 admitted to the hospital required mechanical ventilation (MV) $[2,3]$. Studies reported that reintubation rates of patients with MV in the intensive care unit (ICU) range from 13-19\% [4-6], leading to increased mortality, longer duration of MV, longer ICU stays, and increased costs [7, 8]. Moreover, in patients with COVID-19, intubation is a high-risk procedure because of aerosol generation [9]. In Italy, healthcare workers comprised 9\% of total COVID-19 
patients [10]. Respiratory therapists, intubation providers, and bedside nurses are at highest risk [11]. Reintubation would re-expose health care workers to the virus, all efforts should be made to avoid reintubating patients with COVID-19.

In the previous study, it was reported that preventive high-flow nasal cannula (HFNC) therapy and noninvasive ventilation (NIV) after extubation reduce the risk of reintubation for patients at a high risk of extubation failure who have been receiving MV for more than $24 \mathrm{~h}$ and who have passed a spontaneous breathing trial (SBT) [12-13].

The American College of Chest Physicians/American Thoracic Society (ACCP/ATS) guidelines [14] recommend preventive non-invasive ventilation after extubation for patients at a high risk for extubation failure who are on MV for more than $24 \mathrm{~h}$ and have passed a SBT. However, in patients with COVID-19, the infection-related risks of HFNC therapy and NIV are not well known.

Some reports suggest that the use of HFNC and NIV in patients with COVID-19 should be discouraged because of the risk of aerosol generation and exposure of health care workers [15-16]. Although no studies have directly evaluated the risk of aerosol generation or infection transmission associated with HFNC and NIV use in patients with COVID-19 [17-24], the use of NPPV and HFNC aggravates this risk through continuous open circuit viral aerosolization. If the patient is not in a negative pressure room, viral shedding through aerosol generation can extend beyond the room, thereby contaminating the hallways and beyond. Therefore, the use of NPPV and HFNC for patients with COVID-19 should be minimized and restricted[16].

The ACCP/ATS guidelines [14] recommend that the initial SBT be conducted with inspiratory pressure augmentation (5-8 $\mathrm{cmH}_{2} \mathrm{O}$ ) rather than without inspiratory pressure augmentation (T-piece or continuous positive airway pressure [CPAP]) in acutely hospitalized patients ventilated for more than $24 \mathrm{~h}$. This recommendation places a high value on reducing the duration of $\mathrm{MV}$ and maximizing the probability of extubation success. These reports are based on using HFNC and NPPV after extubation. Without the use of HFNC or NPPV, conventional SBT may overestimate a patient's respiratory status. When we extubate patients with COVID-19, a more accurate assessment of the respiratory status is needed. Some studies reported that a pressure support (PS) of $5 \mathrm{cmH}_{2} \mathrm{O}$ reduces the respiratory workload by $31 \%-38 \%$ [25-26]. Other study reported that a positive end-expiratory pressure (PEEP) of $5 \mathrm{cmH}_{2} \mathrm{O}$ reduces the respiratory workload by up to $40 \%$ in some patients [27-29].

SBT at PS $5 \mathrm{cmH}_{2} \mathrm{O}$ and PEEP $5 \mathrm{cmH}_{2} \mathrm{O}$ may overestimate a patient's reserve capacity. Physiologically minimal PS and PEEP may be lower than conventional SBT.

A meta-analysis that assessed the effort to breathe using various SBT techniques

suggested that highly demanding SBT techniques, such as those with low PS and PEEP, or T-piece accurately reflected a patient's reserve capacity after extubation [30]. 
A highly demanding SBT accurately assesses a patient's reserve capacity and may reduce reintubation rates in patients with COVID-19 without use of HFNC or NPPV. We did not use preventive HFNC or NPPV and extubated patients with COVID-19 with a highly demanding SBT protocol. This study aimed to evaluate whether extubation with a highly demanding SBT protocol can be performed safely.

\section{Methods}

\section{Population and study setting}

This single-centre study was conducted at the Kawasaki Municipal Hospital, which is an emergency and critical care centre in Kawasaki City, located in the south of Kawasaki City in Kanagawa Prefecture. Kawasaki City is a small city with an area of $144 \mathrm{~km}^{2}$ and a population of $1,500,000$. Kawasaki City has one of the highest population densities among all cities in Japan. We engaged in the treatment of patients with COVID-19 in the Diamond Princess at the port of Yokohama in Kanagawa. From February 6, 2020, our hospital had 10 beds for treating severe COVID-19.

\section{Study protocol}

Inclusion criteria included patients who were screened and diagnosed with COVID-19 between February 6, 2020 and June 30, 2020, who required more than 24 h of MV. Exclusion criteria was age $<18$ years. COVID-19 was diagnosed in accordance with the WHO guidelines [1].

The flow chart of the extubation protocol is shown in Fig. 1. Patient eligibility for the extubation procedure was identified by daily screening and SBT. Daily screening was deemed to start immediately after admission. Daily screening was as follows: fraction of inspired oxygen $\left(\mathrm{FiO}_{2}\right)<40 \%$; PEEP $\leq 5 \mathrm{cmH}_{2} 0$; with no or small sedation; and responding to simple orders. Patients who met the daily screening criteria were assessed using SBT. From an infection control standpoint, we avoided the use of T-piece and SBT was performed under the following conditions: $3 \mathrm{cmH}_{2} \mathrm{O}$ pressure support ventilation, $3 \mathrm{cmH}_{2} \mathrm{O}$ PEEP, and $\mathrm{FiO}_{2} \leq 0.30$. SBT was successful when the patient could breathe spontaneously for 30 min without clinical intolerance.

Clinical intolerance was defined as a partial pressure of arterial oxygen $\left(\mathrm{PaO}_{2}\right) \geq 60 \mathrm{mmHg}$; spontaneous tidal volume $\geq 4 \mathrm{ml} / \mathrm{kg}$ predicted body weight; respiratory rate $\leq 35 / \mathrm{min} ; \mathrm{pH} \geq 7.3$; and no respiratory distress (distress $=2$ or more). Respiratory distress was defined as heart rate $>120 \%$ of the baseline; marked accessory muscle use; abdominal paradox; diaphoresis; and marked dyspnea. These clinical intolerances were referenced based on the ARDS Net recommendation [31]. Patients were extubated if they passed SBT. We administered $20 \mathrm{mg}$ of methylprednisolone every $4 \mathrm{~h}$ starting $12 \mathrm{~h}$ before extubation [32]. From an infection control standpoint, we did not enforce cuff leak test. If SBT was not tolerated, the patient was returned to their prior ventilator settings and screened the day after. Successful discontinuation of MV was defined as continuous independence from ventilator support for a period of at least $48 \mathrm{~h}$. Reintubation was performed if any of the following signs were noted: suspected airway stenosis or $\mathrm{PaO}_{2}<60 \mathrm{mmHg}$ with $\mathrm{O}_{2}$ approximately $5 \mathrm{~L}$ (Fig. 1). 


\section{Data collection}

The medical records of patients were analyzed by the COVID-19 research team from the Kawasaki Municipal Hospital. Data of patients who were deemed appropriate for extubation according to the protocol were collected. Data on age, sex, nationality; comorbidities; signs and symptom at the time of onset; laboratory findings; complications, including acute respiratory distress syndrome (ARDS) and ventilator-associated pneumonia (VAP); treatments, including antiviral drugs, antibacterial drugs, corticosteroid therapy, and renal replacement therapy; and outcomes, were obtained from electronic medical records using data collection forms.

Sequential Organ Failure Assessment (SOFA) scores and Acute Physiology and Chronic Health Evaluation II (APACHE II) scores were assessed on the day of ICU admission. Partial pressure of arterial oxygen/fraction of inspired oxygen (P/F ratio) immediately before extubation was determined. ARDS was defined and classified according to the Berlin definition [33]. VAP was defined as the initiation of antibiotics and fulfilment of at least 2 of the following criteria: positive protected bronchoscopy cultures; fever; or increasing leucocyte count [34].

This study was approved by Institutional Review Board and Research Ethics Committee of Kawasaki Municipal Hospital (Approval Number: 2020-17). The requirement for written informed consent was waived.

\section{Outcomes}

Outcomes assessed were the rate of reintubation, overall duration of MV, ICU length of stay, hospital length of stay, and overall incidence of VAP.

\section{Statistical analysis}

Categorical variables are presented as percentages, and continuous variables are presented as mean \pm standard deviation (SD) or median and $25 \%$ and $75 \%$ percentile values. All statistical analyses were undertaken with R statistical software, version 3.3.3 (R Foundation for Statistical Computing Vienna, Austria).

\section{Results}

\section{Presenting characteristics}

Of all patients admitted to our hospital for COVID-19 between February 1, 2020 and June 30, 2020, 10 patients received MV. Two of the 10 patients had no improvement in their respiratory status and did not qualify for the extubation criteria and died. Eight patients were extubated (Fig. 2). Patient characteristics are given in Table 1. The mean age of the patients was $53.6 \pm 11.9$ years, and 8 patients $(100 \%)$ were Japanese males. Seven patients $(87.5 \%)$ had at least one comorbidity. The most common comorbidity was hypertension in 3 cases (37.5\%), followed by diabetes mellitus in 2 cases (25\%), asthma in 2 cases (25\%), chronic kidney disease in 2 cases (25\%), and cardiovascular disease in 1 case (12.5\%). The most 
common symptoms at the onset were fever in 5 cases (62.5\%) and respiratory distress in 5 cases $(62.5 \%)$, dysgeusia in 2 cases (25\%), and cough in one case (12.5\%). At the time of data collection, all the patients were either discharged or deceased.

Table 1

Demographics and clinical characteristics of the patients with COVID-19

\begin{tabular}{|ll|}
\hline & All patients $(\mathbf{n}=\mathbf{8})$ \\
\hline Age (years) & $53.6 \pm 11.9$ \\
\hline Woman, $n(\%)$ & $0(0 \%)$ \\
\hline APACHE II score just before extubation & $10.75 \pm 2.4$ \\
\hline SOFA score just before extubation & $4.125 \pm 1.2$ \\
\hline Japanese, $n$ (\%) & $8(100 \%)$ \\
\hline Comorbidities, $n$ (\%) & \\
\hline Hypertension & $3(37.50 \%)$ \\
\hline Diabetes mellitus & $2(25 \%)$ \\
\hline Asthma & $2(25 \%)$ \\
\hline Chorionic heart failure & $2(25 \%)$ \\
\hline Chronic heart failure & $1(12.50 \%)$ \\
\hline Signs and symptoms & \\
\hline Fever & $5(62.50 \%)$ \\
\hline Dyspnea & $5(62.50 \%)$ \\
\hline Dysgeusia & $2(25 \%)$ \\
\hline Cough & $1(12.50 \%)$ \\
\hline Data are presented as mean \pm standard deviation or count (\%) & \\
\hline APACHE II: Acute Physiology and Chronic Health Evaluation II, SOFA: Sequential Organ Failure \\
\hline Assessment
\end{tabular}

\section{Laboratory test results}

The results of laboratory tests are given in Table 2. The mean leukocyte count was $6.9 \pm 2.0 \times 10^{3} / \mu \mathrm{L}$, and the lymphocyte count was reduced in all $8(100 \%)$ cases. D-dimer, aspartate aminotransferase, alanine 
aminotransferase, lactate dehydrogenase (LDH), ferritin, and C-reactive protein (CRP) levels were elevated in 8 patients (100\%). The mean APACHE II and SOFA scores (SD) were $4.1 \pm 1.2$ and $10.6 \pm 2.4$, respectively. The mean (SD) value of the P/F ratio immediately before extubation was $266.9 \pm 47.7$. 
Table 2

Laboratory findings of 8 patients with COVID-19

\section{Characteristics}

White blood cell $\left(\times 10^{9} / \mathrm{L}\right)$

Neutrophil (\%)

Lymphocyte (\%)

Monocyte (\%)

Platelet $\left(\times 10^{9} / \mathrm{L}\right)$

Prothrombin (\%)

Activated partial thromboplastin time (s)

D-dimer $(\mu \mathrm{g} / \mathrm{mL})$

Creatine kinase (IU/L)

Creatine kinase-MB (IU/L)

Lactate $(\mathrm{mmol} / \mathrm{L})$

Alanine aminotransferase (IU/L)

Aspartate aminotransferase (IU/L)

Lactate dehydrogenase (IU/L)

Total bilirubin $(\mu \mathrm{mol} / \mathrm{L})$

Blood urea nitrogen $(\mathrm{mg} / \mathrm{dL})$

Creatinine $(\mathrm{mg} / \mathrm{dL})$

C-reactive protein $(\mathrm{mg} / \mathrm{L})$

Procalcitonin $(\mathrm{ng} / \mathrm{mL})$

Ferritin $(\mathrm{ng} / \mathrm{mL})$

HbA1c (\%)

$\mathrm{KL}-6(\mathrm{U} / \mathrm{mL})$

Arterial blood gas just before extubation

$\mathrm{pH}$

$\mathrm{P} / \mathrm{F}$ ratio
All patients $(n=8)$

$6.9 \pm 2.0$

$84.0 \pm 6.1$

$8.9 \pm 2.5$

$3.4 \pm 1.8$

$18.1 \pm 3.8$

$89.3 \pm 7.1$

$30.6 \pm 2.9$

$4.7 \pm 6.1$

$304.5 \pm 313.7$

$7.0 \pm 1.4$

$1.2 \pm 0.5$

$87.8 \pm 63.7$

$98.0 \pm 53.0$

$595.3 \pm 167.8$

$0.8 \pm 0.3$

$19.9 \pm 14.0$

$1.3 \pm 0.9$

$19.7 \pm 4.6$

$3.4 \pm 6.6$

$1515.3 \pm 985.7$

$6.5 \pm 0.4$

$462.1 \pm 153.6$

$7.43 \pm 0.04$

$266.9 \pm 47.7$

Data are presented as mean \pm standard deviation. ICU: intensive care unit, $\mathrm{P} / \mathrm{F}$ ratio: ratio of partial pressure of arterial oxygen to the fraction of inspired oxygen 


\section{Complications and treatments}

Complication and treatment details are given in Table 3. Complications included ARDS in 8 patients $(100 \%)$ and VAP in 3 patients (37.5\%). Seven patients had moderate ARDS and 1 had severe ARDS. All patients (100\%) received antibacterial therapy, and 1 patient $(12.5 \%)$ received antiviral therapy (favipiravir). Two patients (25\%) received glucocorticoid therapy; both these patients were diagnosed as having asthma and were treated with glucocorticoid therapy. One patient $(12.5 \%)$ was treated with continuous renal replacement therapy.

Table 3

Complications and treatment of 8 patients with COVID-19

\begin{tabular}{|ll|}
\hline & All patients $(\mathbf{n}=\mathbf{8})$ \\
\hline Complication, $n(\%)$ & $8(100 \%)$ \\
\hline MRDS & $0(0 \%)$ \\
\hline Moderate ARDS & $7(87.5 \%)$ \\
\hline Severe ARDS & $1(12.5)$ \\
\hline VAP & $3(37.5 \%)$ \\
\hline Treatment, $n(\%)$ & $1(12.5 \%)$ \\
\hline Antiviral drug & $8(100 \%)$ \\
\hline Antibiotics & $2(25 \%)$ \\
\hline Corticosteroid & $1(12.5 \%)$ \\
\hline CRRT & \\
\hline Data are presented as mean \pm standard deviation or count $(\%)$. \\
\hline ARDS: acute respiratory distress syndrome, CRRT: continuous renal replacement therapy \\
\hline
\end{tabular}

\section{Outcomes}

The outcomes are given in Table 4. There were no reintubations ( $0 \%)$. The median durations of MV, ICU stay, and hospital stay were 13 (interquartile range [IQR], 10-16) days, 17 (IQR, 13-27) days, and 22 (IQR, 16-26) days, respectively, and 3 patients (37.5\%) had VAP (Table 2 ). 
Table 4

Outcomes of 8 patients with COVID-19

\begin{tabular}{|ll|}
\hline & All patients $\mathbf{( n = 8 )}$ \\
\hline Reintubation, $\mathrm{n}(\%)$ & $0(0 \%)$ \\
\hline Duration of mechanical ventilation, days (IQR) & $13(9.75-16)$ \\
\hline ICU length of stay, days (IQR) & $17(12.5-27)$ \\
\hline Hospital stay, days (IQR) & $22(16.25-26.25)$ \\
\hline The rate of VAP, $\mathrm{n}(\%)$ & $3(37.5 \%)$ \\
\hline Data are presented as median (IQR) or count (\%) & \\
\hline ICU: intensive care unit, IQR: interquartile range, VAP: ventilator-associated pneumonia \\
\hline
\end{tabular}

\section{Discussion}

In our study, all the patients were male and $87.5 \%$ of them had comorbidities, all patients had ARDS complications, and blood samples showed reduced lymphocyte and elevated CRP, LDH, and D-dimer levels. Previous studies have reported that older age, being male, comorbidities, ARDS, reduced lymphocyte, and elevated CRP, LDH, and D-dimer levels correlated with the disease severity in patients with COVID-19 [35-40].

In the present study, we performed highly demanding SBT with $3 \mathrm{cmH}_{2} \mathrm{O}$ PEEP, $3 \mathrm{cmH}_{2} \mathrm{O}$ PS, and $\mathrm{FiO}_{2} 0.3$ and administered steroids to prevent laryngeal edema. All patients were extubated without the use of HFNC or NIV. Previous studies have reported a reintubation rate of $13 \%-19 \%$ [4-6] while in this study reintubation requirement was nil (0\%). Highly demanding SBT possibly reduces reintubation. However, the duration of MV in our study tended to be the same or longer than that in previous studies. In a retrospective case series of 1000 patients in New York, the median duration of MV in patients who survived was 9 (6.5-12) days [3], and another multicentre cohort study of 2215 patients in New York reported that the median duration of MV in patients who survived was $13(9-14)$ days [41]. The median duration of MV for patients in the current study was 13 (IQR, 10-16) days. Some previous studies have reported the length of ICU stay to be approximately 10-20 days [42-43], and the length of ICU stay in the current study was not different from these studies. Although the length of ICU stay was not prolonged, the duration of $\mathrm{MV}$ was tended to prolonge. The protocol used in this study may lead to a prolonged duration of MV.

In a study involving limited patients, the rate of VAP among patients with COVID-19 was approximately $12 \%$ [44]. In our study, the incidence rate of VAP was $37.5 \%$.

The incidence of VAP is reported to vary over time ranging from approximately $3 \%$ per day in the first week of mechanical ventilation, $2 \%$ per day in the second week to $1 \%$ per day in the third week and 
beyond [45]. There are concerns that our protocol led to a prolonged duration of $\mathrm{MV}$ and an increase in the rate of VAP.

It is possible that a highly demanding SBT may lead to reduction in reintubation rates in COVID-19 patients when HFNC and NPPV cannot be used. We successfully extubated all patients without any increase in reintubation rates; however, the use of our protocol may have resulted in prolonged duration of $\mathrm{MV}$ and an increased VAP rate.

This study had some limitations. First, only 8 patients were included. This study had a small sample size. Second, this study used a retrospective observational and non-interventional design, and it did not have a comparator. Third, this study was conducted at a single centre in Kawasaki, Japan. Hence, the results might not be generalizable to other institutions. Fourth, because this study is not a comparative study and does not compare to PEEP/PS used in other studies, a larger number of patients and comparators are needed to examine whether the PS and PEEP used in this study are optimal. Fifth, the incidence of VAP may be inaccurate because the diagnosis was made by individual clinicians. A multicentre clinical trial is needed to demonstrate the benefits of a comprehensive protocol for ventilator weaning and extubation.

\section{Conclusions}

This study suggests that a highly demanding SBT protocol may be safe for extubation without using HFNC and NIV for patients with COVID-19. However, because there is insufficient evidence concerning extubation of patients with COVID-19, further studies are needed to clarify the criteria for extubation.

\section{List Of Abbreviations}

ACCP/ATS: American College of Chest Physicians/American Thoracic Society

APACHE II: Acute Physiology and Chronic Health Evaluation II

ARDS: Acute respiratory distress syndrome

COVID-19: Coronavirus disease 2019

CPAP: Continuous positive airway pressure

CRRT: Continuous renal replacement therapy

CRP: C-reactive protein

$\mathrm{FiO}_{2}$ : Fraction of inspired oxygen

HFNC: High-flow nasal cannula 
HR: Heart rate

ICU: Intensive care unit

IQR: Interquartile range

LDH: Lactate dehydrogenase

MV: Mechanical ventilation

NIV: Non-invasive ventilation

$\mathrm{PaO}_{2}$ : Partial pressure of arterial oxygen

PEEP: Positive end-expiratory pressure

$\mathrm{P} / \mathrm{F}$ ratio: Partial pressure of arterial oxygen/Fraction of inspired oxygen

PS: Pressure support

$\mathrm{RR}$ : respiration rate

SBT: Spontaneous breathing trial

SD: Standard deviation

SOFA score: Sequential organ failure assessment score

VAP: Ventilator-associated pneumonia

WHO: World Health Organization

\section{Declarations}

\section{Ethics approval and consent to participate}

This study was approved by Kawasaki Municipal Hospital (2020-17), and the requirement for written informed consent was waived.

\section{Consent for publication}

Written informed consent for publication was obtained using an opt-out system on the hospital website.

\section{Availability of data and materials}

All data generated or analyzed during this study are included in this published article区. 


\section{Competing interests}

The authors declare that they have no competing interests.

\section{Funding}

The authors declare that no funding was obtained for this study

\section{Authors' contributions}

KS designed the study and had full access to all data of the study and takes responsibility for data integrity and accuracy of data analysis. NF, KK, and YS contributed to data collection and clinical management. KT supervised this study and contributed to the writing of the manuscript. All authors contributed to data acquisition, analysis, or interpretation, and all authors have reviewed and approved the final version of the manuscript.

\section{Acknowledgements}

We thank all the patients, their families, all the doctors, nurses, paramedics, and other medical professionals involved in treatment. We would like to thank Editage for English language editing.

\section{References}

1. World Health Organization. Coronavirus disease (COVID-19) advice for the public. In: Coronavirus disease (COVID-19) pandemic. World Health Organization. 2020. https://www.who.int/emergencies/diseases/novel-coronavirus-2019/advice-for-public. Accessed 30 Jun 2020.

2. Richardson S, Hirsch JS, Narasimhan M, Crawford JM, McGinn T, Davidson KW, et al. Presenting characteristics, comorbidities, and outcomes among 5700 patients hospitalized with COVID-19 in the New York city area. JAMA. 2020;323:2052-59.

3. Argenziano MG, Bruce SL, Slater CL, Tiao JR, Baldwin MR, Barr RG, et al. Characterization and clinical course of 1000 patients with coronavirus disease 2019 in New York: retrospective case series. BMJ. 2020;369:m1996.

4. Esteban A, Frutos F, Tobin MJ, Alía I, Solsona JF, Valverdú I, et al. A comparison of four methods of weaning patients from mechanical ventilation. Spanish Lung Failure Collaborative Group. N Engl J Med. 1995;332:345-50.

5. Esteban A, Alia I, Tobin MJ, Gil A, Gordo F, Vallverdú I, et al. Effect of spontaneous breathing trial duration on outcome of attempts to discontinue mechanical ventilation. Spanish Lung Failure Collaborative Group. Am J Respir Crit Care Med. 1999;159:512-8.

6. Ely EW, Baker AM, Dunagan DP, Burke HL, Smith AC, Kelly PT, et al. Effect on the duration of mechanical ventilation of identifying patients capable of breathing spontaneously. $\mathrm{N}$ Engl J Med. 1996;335:1864-9. 
7. Frutos-Vivar F, Esteban A, Apezteguia C, González M, Arabi Y, Restrepo Ml, et al. Outcome of reintubated patients after scheduled extubation. J Crit Care. 2011;26:502-9.

8. Dasta JF, McLaughlin TP, Mody SH, Piech CT. Daily cost of an intensive care unit day: the contribution of mechanical ventilation. Crit Care Med. 2005;33:1266-71.

9. Cheung JC, Ho LT, Cheng JV, Cham EYK, Lam KN. Staff safety during emergency airway management for COVID-19 in Hong Kong. Lancet Respir Med. 2020;8:e19. doi:10.1016/S22132600(20)30084-9

10. Anelli F, Leoni G, Monaco R, Nume C, Rossi RC, Marinoni G, et al. Italian doctors call for protecting healthcare workers and boosting community surveillance during covid-19 outbreak. BMJ 2020;368:m1254 doi: 10.1136/bmj.m1254

11. Gamio L. The workers who face the greatest coronavirus risk. New York Times 2020.

12. Hernández G, Vaquero C, Colinas L, Cuena R, González P, Canabal A, et al. Effect of postextubation high-flow nasal cannula vs noninvasive ventilation on reintubation and postextubation respiratory failure in high-risk patients: a randomized clinical trial. JAMA. 2016;316:1565-74.

13. Hernández G, Vaquero C, González P, Subira C, Frutos-Vivar F, Rialp G, et al. Effect of postextubation high-flow nasal cannula vs conventional oxygen therapy on reintubation in low-risk patients: a randomized clinical trial. JAMA. 2016;315:1354-61.

14. Ouellette DR, Patel S, Girard TD, Morris PE, Schmidt GA, Truwit JD, et al. Liberation from mechanical ventilation in critically ill adults: an official American College of Chest Physicians/American Thoracic Society Clinical Practice Guideline: inspiratory pressure augmentation during spontaneous breathing trials, protocols minimizing sedation, and noninvasive ventilation immediately after extubation. Chest. 2017;151:166-80.

15. Loh NW, Tan Y, Taculod J, Gorospe B, Teope AS, Somani J, et al. The impact of high-flow nasal cannula (HFNC) on coughing distance: implications on its use during the novel coronavirus disease outbreak. Can J Anesth. 2020;67:893-4.

16. Sullivan EH, Gibson LE, Berra L, Chang MG, Bittner EA. In-hospital airway management of COVID-19 patients. Crit Care. 2020;24:292. Published 2020 Jun 5. doi:10.1186/s13054-020-03018-x

17. Agarwal A, Basmaji J, Muttalib F, Granton D, Chaudhuri D, Chetan D, et al. High-flow nasal cannula for acute hypoxemic respiratory failure in patients with COVID-19: systematic reviews of effectiveness and its risks of aerosolization, dispersion, and infection transmission. Can J Anaesth. 2020;1-32.

18. Hui DS, Chow BK, Lo T, Tsang OTY, Ko FW, Ng SS, et al.Exhaled air dispersion during high-flow nasal cannula therapy versus CPAP via different masks. Eur Respir J. 2019;53.

19. Loh WN, Tan Y, Taculod J, Gorospe B, Teope AS, Somani J, et al. The impact of high-flow nasal cannula (HFNC) on coughing distance: implications on its use during the novel coronavirus disease outbreak. Can J Anesth. 2020;67:893-4.

20. Kotoda M, Hishiyama S, Mitsui K, Tanikawa T, Morikawa S, Takamino A, et al. Assessment of the potential for pathogen dispersal during high-flow nasal therapy. J Hosp Infect. 2020;104:534-7. 
21. Leung CCH, Joynt GM, Gomersall CD, Wong WT, Lee A, Ling L, et al. Comparison of high-flow nasal cannula versus oxygen face mask for environmental bacterial contamination in critically ill pneumonia patients: a randomized controlled crossover trial. J Hosp Infect. 2019;101:84-7.

22. Leonard S, Atwood CW, Jr, Walsh BK, DeBellis RJ, Dungan GC, Strasser W, et al. Preliminary findings on control of dispersion of aerosols and droplets during high-velocity nasal insufflation therapy using a simple surgical mask: implications for the high-flow nasal cannula. Chest. 2020; doi: 10.1016/j.chest.2020.03.043,

23. Iwashyna TJ, Boehman A, Capelcelatro J, Cohn AM, Cooke JM, Costa DK, et al. Variation in aerosol production across oxygen delivery devices in spontaneously breathing human subjects. medRxiv. 2020; doi: https://doi.org/10.1101/2020.04.15.20066688.

24. Roberts S, Kabaliuk N, Spence C, O'Donnell J, Zulkhairi Abidin Z, Dougherty R, et al.Nasal high-flow therapy and dispersion of nasal aerosols in an experimental setting. J Crit Care. 2015;30:842.

25. Sassoon CS, Light RW, Lodia R, Sieck GC, Mahutte CK. Pressure-time product during continuous positive airway pressure, pressure support ventilation, and T-piece during weaning from mechanical ventilation. Am Rev Respir Dis. 1991;143:469-75.

26. Jubran A, Van de Graaff WB, Tobin MJ. Variability of patient-ventilator interaction with pressure support ventilation in patients with chronic obstructive pulmonary disease. Am J Respir Crit Care Med. 1995;152:129-36.

27. Lopez O. Back to basics: critical care transport certification review. Bloomington: Xlibris Corp. 2011.

28. Marino PL. Marino's the ICU book. 4th ed. Philadelphia: Wolters Kluwer Health/Lippincott Williams \& Wilkins; 2014.

29. Vinegar A, Sinnett EE, Leith DE. Dynamic mechanisms determine functional residual capacity in mice, Mus musculus. J Appl Physiol Respir Environ Exerc Physiol. 1979;46:867-71.

30. Sklar MC, Burns K, Rittayamai N, Lanys A, Rauseo M, Chen L, et al. Effort to Breathe with Various Spontaneous Breathing Trial Techniques. A Physiologic Meta-analysis. Am J Respir Crit Care Med. 2017;195:1477-85.

31. ARDS net. NIH NHLBI ARDS clinical network mechanical ventilation protocol summary. 2008. http://www.ardsnet.org/files/ventilator_protocol_2008-07.pdf. Accessed 15 July 2020.

32. François B, Bellissant E, Gissot V, Desachy A, Normand S, Boulain T, et al. 12-h pretreatment with methylprednisolone versus placebo for prevention of postextubation laryngeal oedema: a randomised double-blind trial. Lancet. 2007;369:1083-9.

33. Ranieri VM, Rubenfeld GD, Thompson BT, Ferguson ND, Caldwell E, Fan E, et al; ARDS Definition Task Force. Acute respiratory distress syndrome: the Berlin definition. JAMA. 2012;307:2526-33.

34. Tonnelier JM, Prat G, Le Gal G, et al. Impact of a nurses' protocol-directed weaning procedure on outcomes in patients undergoing mechanical ventilation for longer than 48 hours: a prospective cohort study with a matched historical control group. Crit Care. 2005;9(2):R83-R89.

35. Wang D, Hu B, Hu C, Zhu F, Liu X, Zhang J, et al. Clinical characteristics of 138 hospitalized patients with 2019 novel coronavirus-infected pneumonia in Wuhan, China. JAMA. 2020;323:1061-9. 
36. Li X, Xu S, Yu M, Wang K, Tao Y, Zhou Y, et al. Risk factors for severity and mortality in adult COVID19 inpatients in Wuhan. J Allergy Clin Immunol. 2020;146:110-8.

37. Zheng Z, Peng F, Xu B, Zhao J, Liu H, Peng J, et al. Risk factors of critical \& mortal COVID-19 cases: A systematic literature review and meta-analysis. J Infect. 2020;81:e16-25.

38. Yang $X, Y u Y, X u J$, Shu H, Xia J, Liu H, et al. Clinical course and outcomes of critically ill patients with SARS-CoV-2 pneumonia in Wuhan, China: a single-centered, retrospective, observational study. Lancet Respir Med. 2020;8:475-81.

39. Zhang B, Zhou X, Qiu Y, Feng F, Feng J, Jia Y, et al. Clinical characteristics of 82 death cases with COVID-19. medRxiv. 2020; https://doi.org/10.1101/2020.02.26.20028191.

40. Du Y, Tu L, Zhu P, Mu M, Wang R, Yang P, et al. Clinical features of 85 fatal cases of COVID-19 from Wuhan. A retrospective observational study. Am J Respir Crit Care Med. 2020;201:1372-9.

41. Gupta S, Hayek SS, Wang W, Chan L, Mathews KS, Melamed ML, et al. Factors associated with death in critically ill patients with coronavirus disease 2019 in the US. JAMA Intern Med. 2020; doi: 10.1001/jamainternmed.2020.3596.

42. Zhou F, Yu T, Du R, Fan G, Liu Y, Liu Z, et al. Clinical course and risk factors for mortality of adult inpatients with COVID-19 in Wuhan, China: a retrospective cohort study. Lancet 2020;395:1054-62.

43. Guan WJ, Ni ZY, Hu Y, Liang WH, Ou CQ, He JX, et al. Clinical characteristics of coronavirus disease 2019 in China. N Engl J Med. 2020;382:1708-20.

44. Yang X, Yu Y, Xu J, Shu H, Xia J, Liu H, et al. Clinical course and outcomes of critically ill patients with SARS-CoV-2 pneumonia in Wuhan, China: a single-centered, retrospective, observational study. Lancet Respir Med. 2020;8:475-81.

45. Cook DJ, Walter SD, Cook RJ, Griffith LE, Guyatt GH, Leasa D, Jaeschke RZ, Brun-Buisson C. Incidence of and risk factors for ventilator-associated pneumonia in critically ill patients. Ann Intern Med 1998;129:440.

\section{Figures}




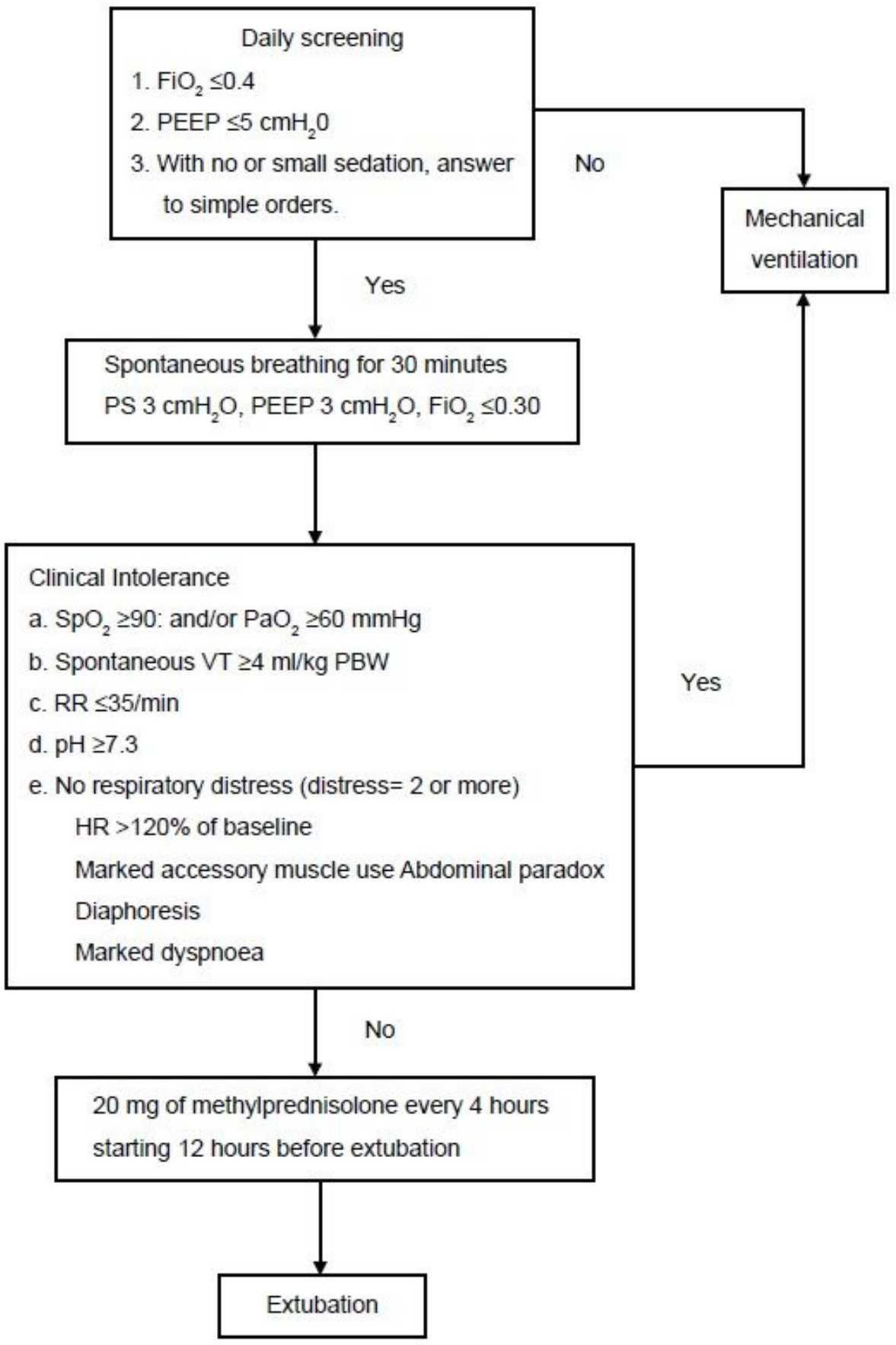

Re-intubation was performed if any of the following signs are noted:

1. Suspected airway stenosis

2. $\mathrm{PaO}_{2}<60 \mathrm{mmHg}$ with $\mathrm{O}_{2}$ about $5 \mathrm{~L}$

\section{Figure 1}

Extubation protocol flow chart. FiO2: fractional inspired oxygen, PEEP: positive end-expiratory pressure, PS: pressure support, RR: respiration rate, HR: heart rate, SBT: spontaneous breathing trial. 


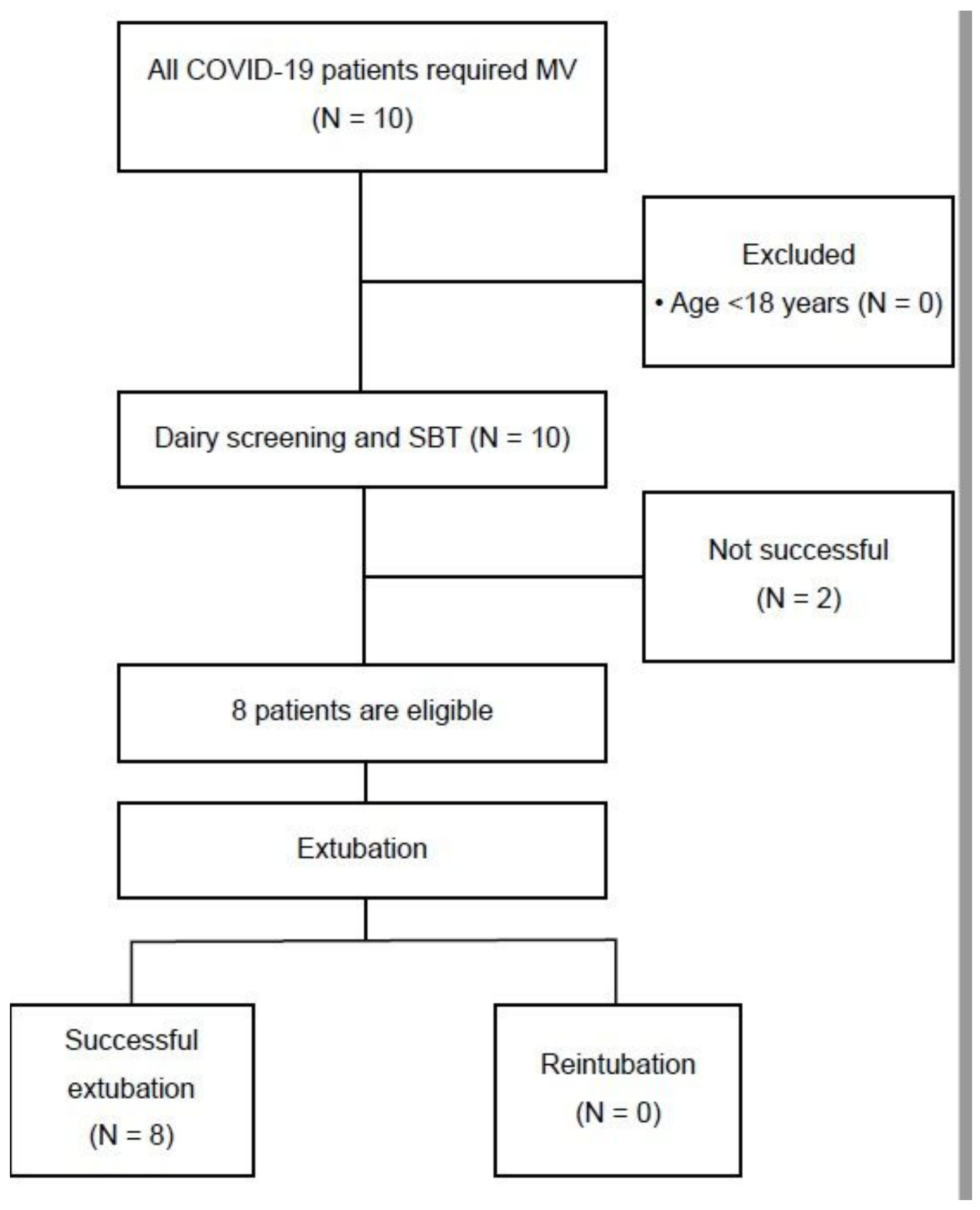

Figure 2

Case selection. COVID-19: Coronavirus disease, MV mechanical ventilation, SBT: spontaneous breathing trial 